\section{A revolução do comum}

Felipe Queiroz ${ }^{1}$ iD [0000-0002-4285-7833]

${ }^{1}$ Universidade Estadual de Campinas, Programa de Pósgraduação em Ciência Política, Campinas, SP, Brasil. $<$ felipequeiroz_braga@hotmail.com>

DARDOT, Pierre; LAVAL, Christian. Comum: ensaio sobre a revolução no século XXI. Trad. Mariana Echalar. São Paulo: Editora Boitempo, 2017. 647.p

Dentre os trabalhos que analisam os movimentos sociais e as lutas políticas contemporâneas contra a apropriação, por parte do grande capital monopolista, dos recursos naturais, dos 'bens comuns', dos espaços e serviços públicos, o livro Comum: ensaio sobre a revolução no século XXI, de Pierre Dardot e Christian Laval, merece destaque tanto pela análise acurada que faz da bibliografia sobre o 'comum' e os 'comuns' quanto pela forma original que pretende 'refundar' o conceito.

O Comum é fruto das pesquisas desenvolvidas pelos autores no seminário Question Marx e do seminário Du publica au commun, organizado pelo Colégio Internacional de Filosofia e pelo Centro de Economia da Sorbonne entre 2010 e 2012. A obra, apesar de abordar uma questão nova, a revolução do comum, pode ser lida e analisada como continuidade de trabalhos anteriores, como A nova razão do mundo (Dardot e Laval, 2016) e Marx, prenon: Karl (Dardot e Laval, 2012). Esses trabalhos, em maior ou menor medida, buscam, por um lado, analisar as condições econômica, política e social do capitalismo contemporâneo e, por outro lado, retomar o pensamento crítico, por meio de uma verdadeira 'arqueologia das ideias'.

O tema da obra é a instituição do comum como elemento central da revolução no século XXI. De acordo com os autores, o comum não é um bem, objeto, lugar ou coisa; antes, ele é uma instituição que se efetiva na esfera coletiva. Diferentemente do que propõem Hardt e Negri (2016), Dardot e Laval entendem que a priori "nada é comum em si ou por natureza" (Dardot e Laval, 2017, p. 618), mas são as práticas coletivas que decidem, em última instância, se uma coisa ou conjunto de coisas devem ser postas na esfera do comum. Situando historicamente, o comum é o princípio que anima a luta política neste início de século XXI, fortalecendo os mais diferentes movimentos sociais e suas lutas democráticas contra o avanço do neoliberalismo.

O conceito possui algumas propriedades distintas: ao mesmo tempo em que ele é o 'princípio político' que dá sentido aos movimentos, às lutas e aos discursos que se contrapõem à racionalidade neoliberal, tão bem descrita em A nova razão do mundo (Dardot e Laval, 2016), ele se apresenta como o resultado dessas lutas, como a efetivação do 'comum'. Além dessas duas propriedades, o conceito se expressa como uma forma democrática nova de governo. Por isso, na análise dos autores, o 'comum' possui três dimensões distintas que se articulam: princípio político, práxis instituinte e governo.

Como princípio político, “o comum exige que a participação [coletiva] numa mesma atividade seja o fundamento da obrigação política, portanto que a coatividade (sic) seja o fundamento da coobrigação" (Dardot e Laval, 2017, p. 616). Essa afirmação é central na análise dos autores, uma vez que o comum jamais se apresenta na forma de um esquema universal ou uma fórmula préestabelecida; antes, ele é produto de uma construção política coletiva com base na qual é possível criar instituições (sociais, políticas, econômicas e jurídicas) do comum que façam oposição entre o novo direito de uso e o direito de propriedade, e estabeleça aquilo que não pode ser apropriado privadamente. Nos termos dos autores, o princípio político do comum delineia "uma norma de inapropriabilidade" (Dardot e Laval, 2017, p. 619, grifo dos autores). Para se instituir essa norma, é preciso refundar todas as relações sociais segundo o princípio de que "a práxis instituinte [irá] determinar o que é inapropriável" (Dardot e Laval, 2017, p. 619-20).

Concomitantemente à efetivação do comum na esfera jurídica, com a criação de um novo direito daquilo que é inapropriável estatal ou privadamente, o comum deve também se estabelecer nas esferas social, política e econômica. Os autores entendem que o comum é um princípio político que tem "vocação a prevalecer tanto na esfera social como na esfera política pública" (Dardot e Laval, 2017, p. 619). Isso significa que existem tanto comuns sociais quanto comuns políticos. O comum político se encarrega de administrar o 'bem comum' em seus diferentes níveis, desde o local ao mundial. 
Na esfera econômica, os autores entendem que o comum deve se efetivar por meio da criação da empresa comum e da emancipação do trabalho, uma vez que "somente será possível liberar o trabalho do domínio do capital se a empresa se tornar uma instituição da sociedade democrática e deixar de ser uma ilha de autocracia patronal e acionária" (Dardot e Laval, 2017, p. 519). Essa afirmação, no entanto, não significa que haverá uma ruptura total nas relações de produção e nas relações sociais de produção, como propõe uma interpretação clássica do marxismo. Os autores entendem que a revolução do comum não é a criação de um novo 'modo de produção', tampouco a superação da propriedade privada, mas a prevalência da empresa comum na economia.

Para os autores, a revolução do comum se apresenta como um processo democrático, plural e construído coletivamente, no qual sua efetivação se dá por meio da práxis instituinte e se mantém por meio do governo democrático do comum. Essa concepção de revolução possui estreita relação com o pensamento de Hannah Arendt e dos autores vinculados à corrente do socialismo associacionista, que vai de Proudhon à Cornelius Castoriádis, passando por Jean Jaurès, Maxim Leroy, Mauss e Gurvitch. Para Castoriádis (apud Dardot e Laval, 2017, p. 611): "revolução não significa nem guerra civil, nem derramamento de sangue. Revolução é uma mudança em certas instituições da sociedade em curto espaço de tempo". Esse é o entendimento dos autores a respeito da revolução do comum.

O projeto de revolução proposto pelos autores, entretanto, não envolve nenhum tipo de transição ou fase intermediária com a participação do Estado. Conforme fora exaustivamente discutido em A nova razão do mundo, os autores apontam acertadamente que o Estado também está enredado na lógica neoliberal e, por isso há “pouca margem à 'adaptação' do capitalismo por meio do direito público e da proteção social em suas bases atuais" (Dardot e Laval, 2017, p. 608). O processo revolucionário, portanto, "só pode ser concebido se for articulado a práticas de natureza muito diversas, isto é, econômicas, sociais, políticas e culturais". (Dardot e Laval, 2017, p. 615). No entanto, a revolução proposta pelos autores apresenta alguns pontos obscuros, sobretudo quando questionamos sobre 'quem' (sujeito) e o 'que fazer' (método). Como bem observou Negri, na análise de Dardot e Laval há um "desenvolvimento idealista" (Negri, 2014, p. 283) do conceito de comum, uma vez que o abandono do materialismo histórico conduz a um desequilíbrio na análise dos autores. Esse aspecto fica evidente quando examinamos juntos os livros A nova razão do mundo e Comum, que pretendem ser continuidade um do outro: em ambos os textos, o conceito de classe social é abandonado e, consequentemente, a análise dos conflitos e lutas entre as classes presentes nas respectivas conjunturas são suprimidas, conduzindo a erros simétricos: ora superestimando, ora subestimando a conjuntura política, econômica e social.

Na primeira obra (A nova razão do mundo), o neoliberalismo é descrito como um processo inexoravelmente totalizador que abarca desde os Estados nacionais até as subjetividades individuais. Em nenhum momento, há referência de quem (ou qual classe) possa estar ganhando com a perpetuação desse cenário, ou seja, não há Estados, nem classes, nem grupos organizados: há apenas instituições e sujeitos individualizados que agem como autômatos do neoliberalismo em constante luta pela valorização do capital individual.

Em Comum, o cenário traçado é totalmente inverso. Apesar de apontar, ainda que minimamente, a influência do capital contemporâneo na construção das subjetividades dos sujeitos, o cenário traçado é exageradamente otimista. Enquanto tendem a reduzir a importância dos conflitos e confrontos entre classes e frações de classes sociais que ocorrem nessa fase do neoliberalismo, eles não conseguem desenvolver satisfatoriamente suas análises sobre a natureza da ruptura que levaria do atual cenário sombrio do neoliberalismo - tão bem descrito em A nova razão do mundo - ao governo do comum.

Por isso, entendemos ser possível fazer duas diferentes leituras sobre a revolução do comum: na primeira, a revolução pode ser pensada metaforicamente como o desfecho do filme o Clube da luta, de David Fincher, com a implosão simultânea do capitalismo em diversas partes do mundo, por meio da práxis do comum. Essa leitura, porém, não exclui as lutas individuais, locais e coletivas espalhadas por todo o mundo, desde a Primavera Árabe até o Ocuppy Wall Street, além de abarcar todas as três propriedades do conceito de comum (princípio político, práxis instituinte e autogoverno) no âmbito da luta política. Em certo sentido, podemos ver similitudes entre essa forma de revolução do comum e a revolução da multidão proposta por Hardt e Negri (2016), pois ambas 
compreendem que as forças para derrubada do capital estão em curso; e os Estados, os grandes oligopólios econômicos e o capital financeiro subestimam o potencial revolucionário dessa força social. No entanto, cabe frisar que a proposta dos autores não envolve uma total radicalidade em relação à superação da propriedade privada e à construção de uma nova sociedade do comum.

Deste ponto específico decorre a segunda leitura do conceito de revolução de Dardot e Laval: uma revolução gradual, que se efetivaria paulatinamente, por meio de conquistas políticas contínuas. Na última parte do livro, na qual os autores apresentam nove proposições políticas para efetivação do comum, é defendido que, primeiramente, deve surgir uma 'política do comum', que faça do comum o princípio de transformação social (proposição 1) e uma nova norma jurídica que afirme a oposição entre o novo direito de uso e o direito de propriedade (proposição 2). A emancipação do trabalho (proposição 3), a criação da empresa comum (proposição 4) e a associação (proposição 5) entre os produtores do comum são elementos que devem predominar na esfera da economia e se efetivariam baseados nas duas primeiras proposições. A efetivação de uma democracia social (proposição 6) e a transformação dos bens e serviços públicos em instituições do comum (proposição 7) ocorreriam na sequência. Numa perspectiva mundial, porém, os auto- res defendem a efetivação de comuns mundiais (proposição 8) e a instituição de uma federação mundial dos comuns (proposição 9).

O Comum, de Dardot e Laval, apesar de apenas delinear alguns possíveis caminhos para efetivação da revolução do comum, apresenta uma importante contribuição para aqueles compromissados com as lutas democráticas contemporâneas.

\section{Referências}

DARDOT, Pierre; LAVAL, Christian. A nova razão do mundo: ensaio sobre a sociedade neoliberal. Tradução Mariana Echalar. São Paulo: Editora Boitempo, 2016.

DARDOT, Pierre; LAVAL, Christian. Marx, prenóm: Karl. Paris: Gallimard, 2012.

DARDOT, Pierre; LAVAL, Christian. Comum: ensaio sobre a revolução no século XXI. Tradução Mariana Echalar. São Paulo: Editora Boitempo, 2017.

HARDT, Michael; NEGRI, Antonio. Bem-estar comum. Rio de Janeiro: Record, 2016.

NEGRI, Antonio. Comum, entre Marx e Proudhon. Lugar comum - estudos em mídia, cultura e democracia, Rio de Janeiro, n. 43, p. 282-286, mai-ago-2014. 